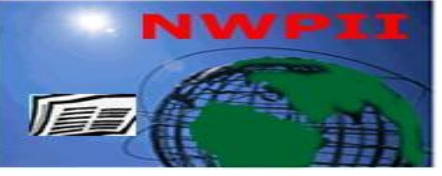

American Journal of Biomedical Sciences

ISSN: 1937-9080

nwpii.com/ajbms

\title{
Exercise Training Prevents Coronary Endothelial Dysfunction in Type 2 Diabetic Mice
}

\author{
Sewon Lee, Yoonjung Park and Cuihua Zhang*
}

Departments of Internal Medicine, Medical Pharmacology \& Physiology, and Nutrition and Exercise Physiology, Dalton Cardiovascular Research Center, University of Missouri-Columbia, MO 65211

*Corresponding Author:

Cuihua Zhang, MD, PhD

Division of Cardiovascular Medicine

Department of Internal Medicine, Medical

Pharmacology \& Physiology, and Nutrition and Exercise Physiology

Dalton Cardiovascular Research Center

University of Missouri-Columbia

Columbia, MO 65211

Phone: 573-882-2427

Fax: 573-884-4232

E-mail address: zhangcu@ missouri.edu

Received: 10 June 2011; $\mid$ Revised: 27 June 2011; $\mid$ Accepted: 6 July 2011

\begin{abstract}
Type 2 diabetes (T2D) is a leading risk factor for cardiovascular diseases including atherosclerosis and coronary heart disease. Exercise training (ET) is thought to have a beneficial effect on these disorders, but the basis for this effect is not fully understood. Because endothelial dysfunction plays a key role in the pathological events leading to cardiovascular complications in T2D, we hypothesized that the effects of ET will be evidenced by improvements in coronary endothelial function. To test this hypothesis, we assessed the effects of ET on vascular function of diabetic $\left(d b / d b\right.$, Lepr $\left.^{d b}\right)$ mice by evaluating endothelial function of isolated coronary arterioles of wild-type (WT) and $d b / d b$ mice with/without ET. Although dilation of vessels to the endothelial-independent vasodilator, sodium nitroprusside was not different between $d b / d b$ and WT, dilation to the endothelial-dependent agonist, acetylcholine (ACh), was impaired in $d b / d b$ compared to WT mice. Vasodilation to ACh was restored in $d b / d b$ with ET and insulin sensitivity was improved in the $d b / d b$ after ET. Exercise did not change body weight of $d b / d b$, but superoxide dismutase (SOD1 and SOD2) and phosphorylated- eNOS protein (Ser1177) expression in heart tissue was up-regulated whereas tumor necrosis factor-alpha (TNF- $\alpha$ ) protein level was decreased by ET. Serum level of interleukin-6 (IL-6) was higher in $d b / d b$ mice but ET decreased IL-6. This suggests that ET may improve endothelial function by increasing nitric oxide bioavailability as well as decreasing chronic inflammation. We suggest this connection may be the basis for the benefit of ET in T2D.
\end{abstract}

Keywords: cardiovascular disease, inflammation, superoxide, anti-oxidants, vascular biology. 


\section{Introduction}

Type 2 diabetes (T2D) is one of the major risk factors for cardiovascular diseases (CVD) and CVD is the leading cause of death worldwide [1,2]. Diabetic patients have a 2- to 4 fold higher incidence of coronary artery disease and a $\sim 10$ fold increase in peripheral diseases owing to accelerated atherogenesis [3,4]. Endothelialdependent vasodilation is markedly reduced in both animal and human type 2 diabetic subjects [5-9]. Blood flow, in general, is regulated by the influence of several constrictors and dilators from endothelium [10]. Endothelial dysfunction is considered as an early predictor of various CVD such as atherosclerosis and heart attack and has been implicated in the pathogenesis of diabetesinduced angiopathy [11]. Accumulating evidence shows that endothelial dysfunction results in an oxygen imbalance of myocardial demand and supply that may lead to cardiac ischemia and infarction [12-14].

Oxidative stress is tightly managed within a narrow range via regulatory mechanisms that balance reactive oxygen species (ROS) production with ROS removal by anti-oxidant enzymes such as superoxide dismutase (SOD) $[15,16]$. Excessive ROS contributes to damage to DNA, lipids, and proteins, and disrupts cardiovascular reactivity [3]. Nitric oxide (NO) produced by vascular endothelium regulates vasodilation, anticoagulation, leukocyte adhesion and smooth muscle proliferation in the vasculature [3,17]. Hyperglycemia has been reported to decrease NO bioavailability by increasing production of ROS [17]. This suggests the preservation of NO bioavailability represents a therapeutic target for managing diabetes-induced coronary artery disease.

In addition, many studies have demonstrated that atherosclerosis is a chronic inflammatory disease involving a complex interplay between vascular cells (endothelial and smooth muscle cells) and infiltrating immune cells such as macrophages $[18,19]$. Macrophages infiltrating into endothelial and smooth muscle cells secrete pro-inflammatory cytokines such as tumor necrosis factor-alpha (TNF- $\alpha$ ) and interleukin-6
(IL-6), and these products exacerbate the risk of endothelial dysfunction and atherosclerosis $[18,19]$.

The beneficial effects of exercise training (ET) on type 2 diabetic patients are well established. For example, exercise improves energy metabolism and insulin sensitivity, which suggests that ET remediates conditions that lead to glucose and lipid dysregulation [20]. However, the mechanisms by which ET ameliorates coronary vascular function in T2D via suppression of oxidative stress and inflammation are not completely elucidated. Thus, we hypothesized that ET will improve coronary endothelial function by suppressing oxidative stress and inflammation in a T2D murine model and tested this by investigating underlying mechanisms involved in improvement of endothelial function.

\section{Methods}

\subsection{Animals}

The procedures were designed in accordance with approved guidelines set by the Laboratory Animal Care Committee at the University of Missouri-Columbia. Five week old male wild-type mice (WT, Background Strain: C57BLKS/J) and homozygous type 2 diabetic mice $\left(d b / d b\right.$, Lepr ${ }^{d b}$, Background Strain: C57BLKS/J) were purchased from Jackson Laboratory and were housed in an animal facility conditioned with 12:12 hours lightdark cycles and allowed free access to normal chow (Research diet, D10012M) and water. Diabetic mice were randomly divided into exercised (ET) or sedentary treatments. All ET and sedentary animals were sacrificed at the age of 16-17 weeks old. Body weights and non-fasting blood glucose levels with commercial One Touch UltraSmart glucometer (Lifescan, Milpitas, CA) were recorded on weekly basis.

\subsection{Exercise performance test}

Exercise performance testing was previously described in detail $[15,21]$. Briefly, all mice were acclimatized to run on a motorized rodent treadmill with an electric grid at the rear of the treadmill (Columbus Instruments, Columbus, $\mathrm{OH}$ ) 2 days prior to conducting exercise performance testing. For the performance test, mice were 
placed on the treadmill and allowed to adapt to the surroundings for 3-5 minutes; then the treadmill was started at a speed of $8.5 \mathrm{~m} /$ minute with a $0^{\circ}$ incline. After 5 minutes, the speed was raised to $10 \mathrm{~m} / \mathrm{minute}$. Speed was then increased by $2.5 \mathrm{~m} /$ minute every 3 minutes to a maximum of $30 \mathrm{~m} / \mathrm{minute}$.

\subsection{Exercise training}

Diabetic mice assigned to the exercise group were exposed to 10 weeks of training consisting of treadmill running 5 days/week, 60 minutes/day at a final intensity equivalent to approximately $50 \%$ of $\mathrm{VO}_{2 \mathrm{Max}}$ attained during the exercise performance test. To allow for animal acclimatization, exercise intensity was gradually increased over the first 4 weeks to reach a target of 1hour of daily exercise at a speed of $10 \mathrm{~m} / \mathrm{minute}$. A daily 60 minute exercise consisted of a 10minute warm-up, a 45 minute-run and a 5-minute cool-down [15].

\subsection{Dual-Energy X-ray Absorptiometry (DEXA)}

One week prior to sacrifice, all mice were anesthetized with isoflurane and whole-body compositions such as fat and lean mass were measured using a Hologic QDR-1000 with the DEXA machine calibrated for mice.

\subsection{Measurement of blood parameters: cholesterol, CRP and IL-6}

Blood was obtained from the vena cava after anesthesia with sodium pentobarbital $(50 \mathrm{mg} / \mathrm{kg}$ intraperitoneal). A whole blood sample was placed for 30 minutes at room temperature to allow clotting. The sample was then centrifuged at 2,000-3,000 x $g$ for 10 minutes at $4{ }^{\circ} \mathrm{C}$; the serum was collected in separate tubes without disturbing blood clots and stored at $-80^{\circ} \mathrm{C}$ until analysis. The serum cholesterol level was measured with the Cholesterol/Cholesteryl Ester Quantitation Kit (Biovision) and the serum C-reactive protein (CRP) and IL-6 levels were measured with commercial kits (Alpco Diagnostics) using spectrophotometry according to manufacturer's instructions.

\subsection{Measurement of TNF- $\alpha$ using ELISA}

TNF- $\alpha$ protein levels were determined by commercial enzyme-linked immunosorbent assay (ELISA) kit (R\&D systems) using heart homogenate. Observance values from ELISA were normalized to total protein concentration using the $\mathrm{BCA}^{\mathrm{TM}}$ protein Assay Kit (Pierce).

\subsection{Insulin Tolerance Test}

The tail tip was cut horizontally with sterile scissors and baseline blood glucose was measured using OneTouch Ultramini glucometer (Lifescan). Diluted insulin (porcine pancreas; 1 unit/kg body weight; Sigma) was injected into the intraperitoneal (I.P) cavity after overnight fasting. Blood glucose was measured from the tail of each mouse at $0,60,90$ minutes by gently massaging a small drop of blood onto the glucometer strip.

\subsection{Citrate Synthase Activity}

To measure the effect of ET, soleus muscles were harvested from mice hindlimb and citrate synthase activity was assessed by Citrate Synthase Assay Kit (Sigma) according to manufacturer's instructions.

\subsection{Functional Assessment of isolated coronary arterioles}

The techniques for identification and isolation of coronary arterioles were previously described in detail [7]. Briefly, the hearts from 3 groups of animals, WT, $d b / d b$ and $d b / d b+\mathrm{ET}$ mice were collected and immediately placed in cold $\left(4^{\circ} \mathrm{C}\right)$ saline solution. Each coronary arteriole (50$100 \mu \mathrm{m}$ in internal diameter) was carefully isolated and cannulated with glass micropipettes. To assess the function of coronary arterioles, vessels were intraluminally pressurized at $60 \mathrm{cmH}_{2} \mathrm{O}$ without flow. After developing a basal tone, the experimental interventions were performed. The concentration-diameter relationships for an activator of endothelial-dependent vasodilation, acetylcholine (ACh, $1 \mathrm{nmol} / \mathrm{L}$ to $10 \mu \mathrm{mol} / \mathrm{L})$, and endothelial-independent, NO donor, sodium nitroprusside (SNP, $1 \mathrm{nmol} / \mathrm{L}$ to $10 \mu \mathrm{mol} / \mathrm{L}$ ) were performed in the presence of NOS inhibitor, $N P^{\mathrm{GPP}}$-nitro-l-arginine-methyl ester (L-NAME, $10 \mu \mathrm{mol} / \mathrm{L}, 20 \mathrm{~min})$, or in the presence of hydroxy-2,2,6,6-tetramethylpiperidinyloxy 
(TEMPOL, $1 \mathrm{mmol} / \mathrm{L}, 1 \mathrm{hr})$, TNF- $\alpha(1 \mu \mathrm{g} / \mathrm{mL}$, $1 \mathrm{hr})$ and IL-6 $(5 \mu \mathrm{g} / \mathrm{mL}, 30 \mathrm{~min})$ prior to beginning the protocols. At the end of each experiment, the vessel was exposed to $100 \mu \mathrm{mol} / \mathrm{L}$ SNP to obtain its maximal diameter at $60 \mathrm{cmH}_{2} \mathrm{O}$ intraluminal pressure.

\subsection{Western blot analyses}

For western blot analysis, the heart was separately homogenized and sonicated in lysis buffer (Cellytic MT Mammalian Tissue Lysis/Extraction Reagent, Sigma) with protease and phosphotase inhibitors (Sigma) at 1:100 ratios, respectively. Protein concentrations were assessed with $\mathrm{BCA}^{\mathrm{TM}}$ protein Assay Kit (Pierce). Equal amounts of protein $(40 \mu \mathrm{g}$ or $100 \mu \mathrm{g})$ were separated by $12 \%$ or $7.5 \%$ SDS-PAGE and transferred to PVDF or nitrocellulose membranes (Bio-Rad). Phosphorylated (phospho, Ser1177) endothelial nitric oxide synthase (eNOS), eNOS, superoxide dismutase (SOD)-1, SOD-2 and GAPDH protein expressions were detected by western blot analysis with the use of phosphoeNOS primary antibody (Santa Cruz, 1:200), eNOS (Santa Cruz, 1:200), SOD-1 primary antibody (Calbiochem, 1:1000), SOD-2 primary antibody (Calbiochem 1:1000) and GAPDH (Imagenex, 1:2000). Horseradish peroxidase (HRP)-conjugated secondary antibodies were accordingly used. Signals were visualized by enhanced chemiluminescence (ECL, Bio-Rad), scanned with a Fuji LAS 3000 densitometer. The relative amounts of protein expression were quantified and normalized to those of the corresponding internal reference, GAPDH and then normalized to corresponding WT, which were set to a value of 1.0 .

\subsection{Data analysis}

At the end of each experiment, the vessel was exposed to $100 \mu \mathrm{mol} / \mathrm{L} \mathrm{SNP}$ to obtain its maximal diameter at $60 \mathrm{~cm} \mathrm{H}_{2} \mathrm{O}$ intra-luminal pressure. All diameter changes to pharmacological agonists were normalized to the control diameter. Statistical comparisons of vasomotor responses under various treatments and insulin tolerance test responses were analyzed by two-way ANOVA with repeated measures. The significance of differences among groups observed in relative protein content was evaluated by one-way ANOVA using SPSS17. Statistical differences were considered significant at the $p<0.05$ or $\mathrm{P}<0.01$ probability level.

\section{Results}

\subsection{General characteristics and serum parameters of mice}

Diabetic mice showed higher body mass, \% body fat, fat mass, and blood glucose, whereas they exhibited lower lean mass compared to WT mice. However, exercise did not alter these parameters in $d b / d b$ mice (Table1). As an indicator of the physiological effectiveness of our exercise protocol, citrate synthase activity was significantly increased in exercised $d b / d b$ mice but there were no significant differences between WT and $d b / d b$ mice (Table1). An insulin tolerance test was performed after 9 weeks of exercise regimen in $d b / d b$ mice. We showed in a previous study that diabetic mice were significantly insulin intolerant compared to WT and exercise partially improved insulin intolerance in $d b / d b$ mice (Figure1). Lowgrade inflammation marker, CRP and total cholesterol were increased in $d b / d b$ serum. Exercise did not change CRP whereas it partially decreased total cholesterol in $d b / d b$ mice (Table1).

\subsection{Role of exercise training in coronary arteriolar function in type $\mathbf{2}$ diabetes}

Consistent with previous studies, AChinduced endothelial-dependent vasodilation was attenuated in coronary arterioles in $d b / d b$ mice compared to WT. Administration of 10 weeks ET completely restored vasodilation in $d b / d b$ mice (Figure 2A). Dilation to the NO donor, SNP in WT, $d b / d b$ and $d b / d b+\mathrm{ET}$ was identical (Figure 2B).

\subsection{Role of exercise in NO bioavailability}

Coronary arterioles were incubated with the nitric oxide synthase (NOS) inhibitor, L-NAME, which significantly inhibited vasodilation to $\mathrm{ACh}$ in WT and $d b / d b+\mathrm{ET}$, whereas dilation was not altered in $d b / d b$ mice (Figure 3A). Our western blotting data showed that total eNOS protein expression was not changed by diabetic status and exercise. In addition, phosphorylated eNOS at 
Ser1177 was not changed by diabetic status but with exercise in $d b / d b$ mice (Figure 3B). eNOS phosphorylation at Ser1177 was increased

Table 1. Basic characteristics of WT and $d b / d b$ mice

\begin{tabular}{|c|c|c|c|}
\hline & $W T$ & $d b / d b$ & $d b / d b+\mathbf{E T}$ \\
\hline $\mathbf{N}$ & $6-9$ & $6-12$ & $7-11$ \\
\hline Body mass (g) & $26.95 \pm 0.56$ & $39.73 \pm 0.67 *$ & $39.38 \pm 0.74 *$ \\
\hline$\%$ Body Fat & $23.78 \pm 2.18$ & $63.85 \pm 0.47^{*}$ & $64.64 \pm 0.59^{*}$ \\
\hline Fat Mass (g) & $7.03 \pm 0.72$ & $25.74 \pm 0.54 *$ & $26.05 \pm 0.54 *$ \\
\hline Lean Mass (g) & $22.43 \pm 0.79$ & $14.54 \pm 0.59 *$ & $14.25 \pm 0.38^{*}$ \\
\hline $\begin{array}{l}\text { Citrate Synthase Activity } \\
\text { Unit }(\mu \mathrm{mole} / \mathrm{ml} / \mathrm{min})\end{array}$ & $212.78 \pm 8.39$ & $180.58 \pm 13.32$ & $238.79 \pm 7.54 \#$ \\
\hline Blood Glucose (mg/dl) & $137.83 \pm 9.50$ & $424.67 \pm 34.81^{*}$ & $402.27 \pm 29.97 *$ \\
\hline Total Cholesterol $(\mu \mathrm{g} / \mu \mathrm{l})$ & $1.27 \pm 0.20$ & $2.70 \pm 0.12 *$ & $2.03 \pm 0.14 * \#$ \\
\hline C-Reactive Protein (ng/ml) & $19.99 \pm 0.67$ & $24.25 \pm 0.50 *$ & $25.84 \pm 0.53 *$ \\
\hline
\end{tabular}

Table 1. The body mass, $\%$ body fat, fat and lean mass, citrate synthase activity, blood glucose level, serum total cholesterol and C-reactive protein were examined in WT and $d b / d b$ mice with/without ET. Diabetic mice $(d b / d b)$ showed higher body mass, \% body fat, fat mass, and blood glucose, whereas they exhibited lower lean mass compared to WT mice. Citrate synthase activity was significantly increased in exercised $d b / d b$ mice but there were no significant differences between WT and $d b / d b$ mice. Low-grade inflammation marker, CRP and total cholesterol were increased in $d b / d b$ serum. ET did not change CRP whereas it decreased total cholesterol in $d b / d b$ mice. Data represent means \pm SE. WT, wild-type; ET, exercise training; CRP, C-reactive protein. $* \mathrm{P}<0.05$ compared with WT. \#P $<0.05$ compared with $d b / d b$.

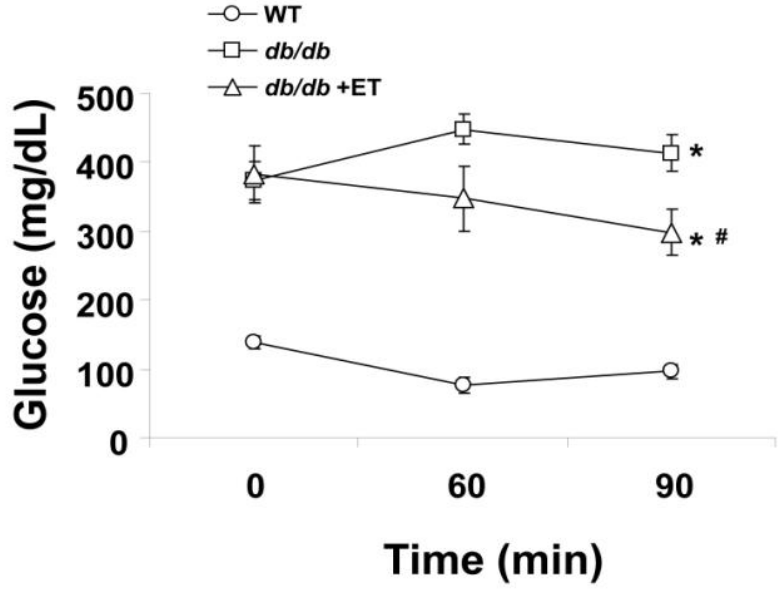

Figure 1. Insulin tolerance test was performed after 9 weeks treadmill exercise. Diabetic mice $(d b / d b)$ showed insulin resistance compared to WT. Exercise partially improved insulin sensitivity in $d b / d b$ mice $(\mathrm{n}=6-11)$. ET, exercise training; WT, wild-type. $* \mathrm{P}<0.01$ vs $\mathrm{WT}$. \#P $<0.05$ vs $d b / d b$.

\subsection{Role of anti-oxidants in coronary arteriolar function in type 2 diabetes}

Coronary arterioles were incubated with the superoxide scavenger, TEMPOL, which restored endothelial function in $d b / d b$ mice (Figure 4A). Endogenous antioxidants, SOD-1 and SOD-2 protein expression in the heart were lower (but not significantly) in diabetic mice compared to WT mice. Exercise significantly increased SOD-1 and SOD-2 in $d b / d b$ mice (Figure 4B and C). 

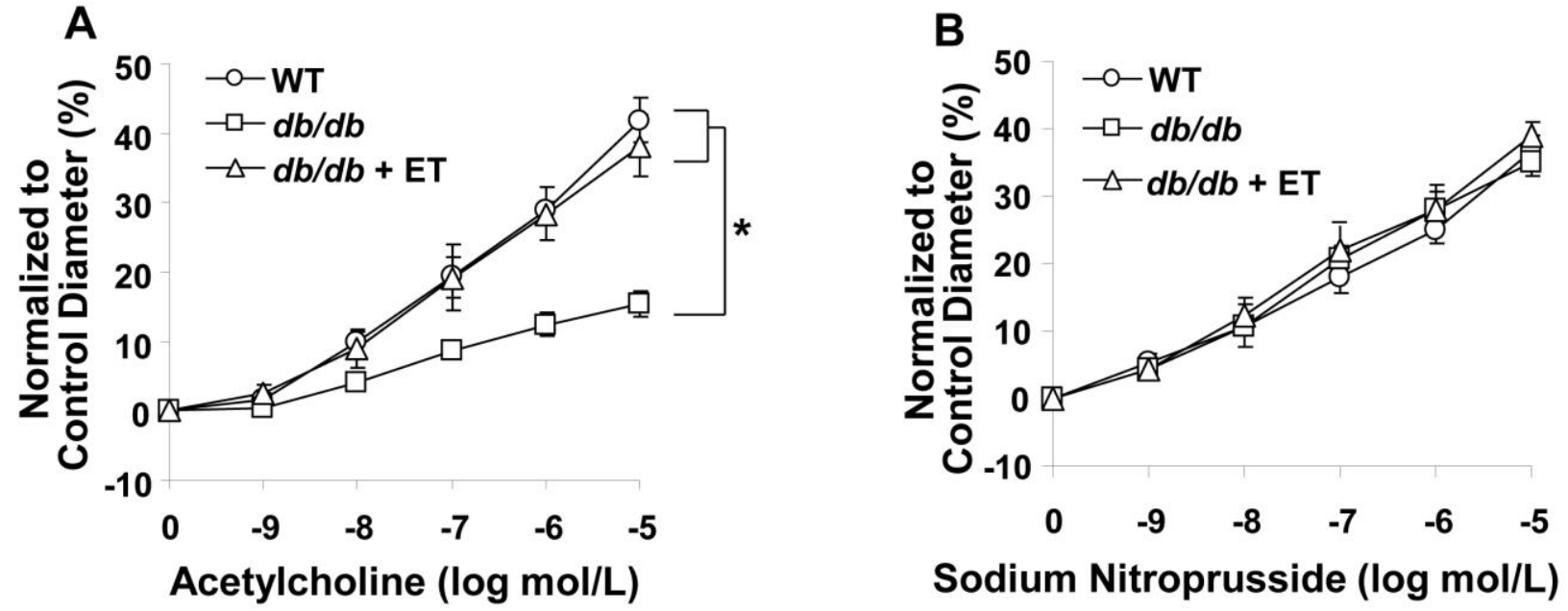

Figure 2 A. Isolated coronary arterioles from WT and $d b / d b$ mice were dilated in response to ACh in a concentrationdependent manner. ACh-induced vasodilation was significantly attenuated in $d b / d b$ mice compared to WT mice. However, 10 weeks ET completely restored ACh-induced vasodilation of diabetic coronary arterioles. B. The endothelial-independent vasodilator (NO donor), SNP-induced vasodilation was not significantly different among groups. $\mathrm{n}=8-17$. ACh, acetylcholine; $\mathrm{SNP}$, sodium nitroprusside. ${ }^{*} \mathrm{P}<0.01 \mathrm{vs} d b / d b$.
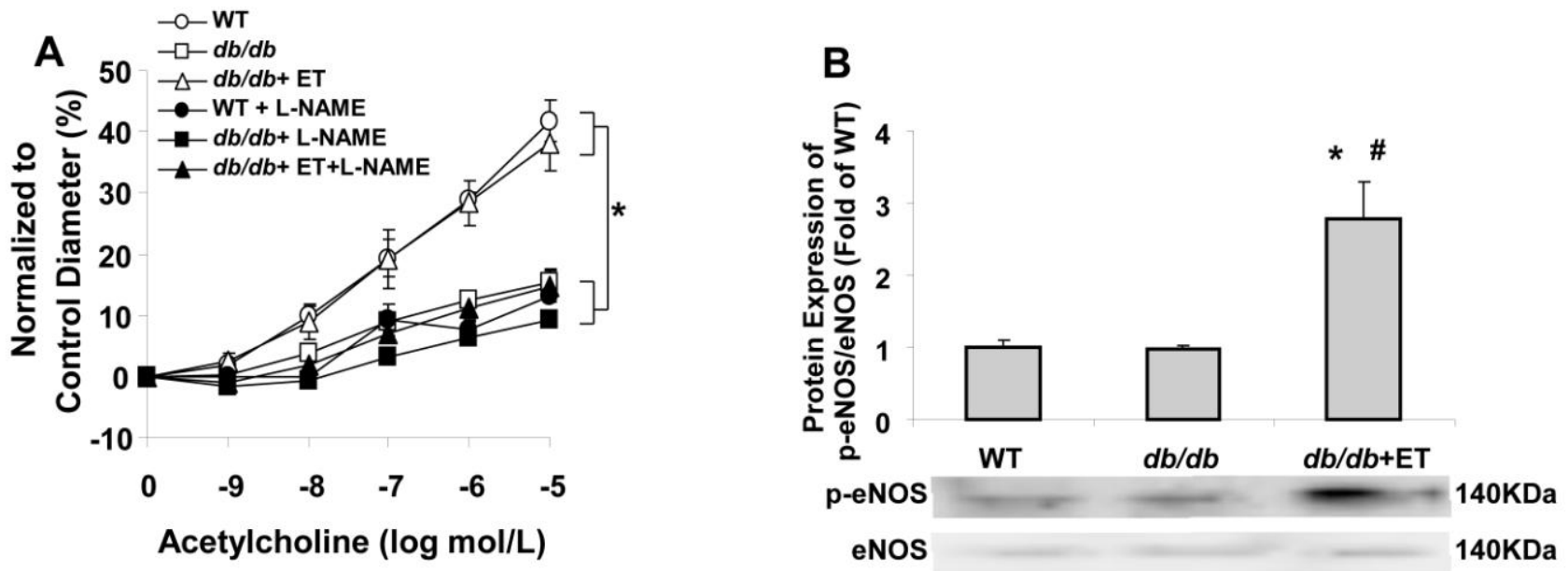

Figure 3 A. Incubation of $N P P^{\mathrm{GPP}}$-nitro-l-arginine-methyl ester (L-NAME; 10 $\mu \mathrm{mol} / \mathrm{L}, 20 \mathrm{~min}$ ) significantly reduced ACh-induced dilation in WT, $d b / d b+\mathrm{ET}$ but not in $d b / d b$ mice $(\mathrm{n}=3-17)$. B. Protein expression of endothelial nitric oxide synthase (eNOS) in heart homogenate was identical among groups. Phosphorylated Ser 1177 protein expression did not changed by diabetic status, but ET increased phosphor-eNOS protein expression in $d b / d b$ mice $(\mathrm{n}=6)$. $* \mathrm{P}<0.05$ vs WT. \#P<0.05 vs $d b / d b$.

3.5 Role of pro-inflammatory cytokines in coronary arteriolar function in type 2 diabetes

ACh-induced vasodilation was greater than in WT and $d b / d b+$ ET mice compared to that in $d b / d b$ mice. TNF- $\alpha$ or IL-6 incubation impaired endothelial-dependent vasodilation in WT and $d b / d b+\mathrm{ET}$, whereas this incubation did not further impair endothelial-dependent vasodilation in arterioles from $d b / d b$ mice (Figure 5A and B). To test whether ET could decrease TNF- $\alpha$ and IL-6 
production, TNF- $\alpha$ and IL-6 protein levels were determined by ELISA. TNF- $\alpha$ protein significantly increased in $d b / d b$ heart homogenate compared to WT, exercise decreased TNF- $\alpha$ protein levels in the $d b / d b$ heart (Figure 5C).
Similarly, serum protein level of IL-6 was higher in $d b / d b$ compared to WT and exercise lowered (but not significantly) serum protein level of IL-6 in $d b / d b$ mice $(\mathrm{P}=0.155)$ (Figure $5 \mathrm{D})$.
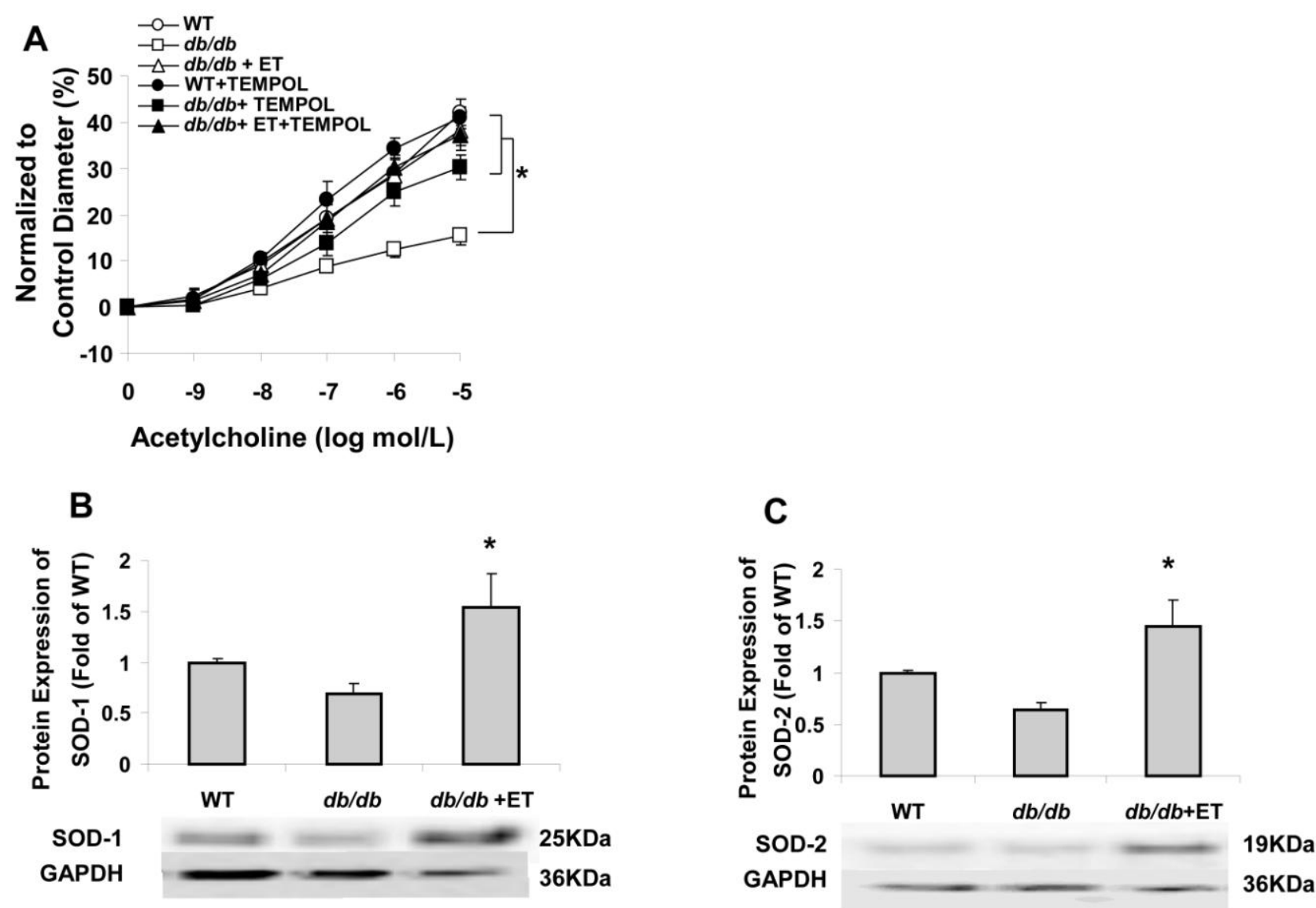

Figure 4 A. Incubation of hydroxy-2, 2, 6, 6-tetramethylpiperidinyloxy (TEMPOL, a superoxide dismutase mimetic; $1 \mathrm{mmol} / \mathrm{L}, 1$ hour) partially restored vasodilation in $d b / d b$ mice but not in WT and $d b / d b+\mathrm{ET}$. $\mathrm{n}=3-17 \mathbf{B}-\mathbf{C}$. ET increased superoxide dismutase (SOD)-1 and 2 protein expressions in $d b / d b$ mice. $\mathrm{n}=6-12$. $* \mathrm{P}<0.05$ vs $d b / d b$.

\section{Discussion}

Hyperglycemia in diabetes results in oxidative stress and low-grade chronic inflammation [22-24]. Excessive oxidative stress and chronic inflammation are major pathogenic characteristics of diabetes-induced vascular complications $[16,24,25]$. Previous studies have shown that oxidative stress and inflammation play important roles in the development of endothelial dysfunction in diabetes [1,26-28]. Oxidative stress arises from an imbalance when the production of ROS exceeds that of endogenous anti-oxidant enzymes [10,16,29]. Excessive ROS such as superoxide are highly reactive with $\mathrm{NO}$ and decrease the bioavailability of $\mathrm{NO}$ in the vasculature $[17,30]$. Thus, factors that increase NO bioavailability via anti-oxidants as well as improved production of vasodilators may be important therapeutic targets for preserving endothelial function in type 2 diabetic patients. 

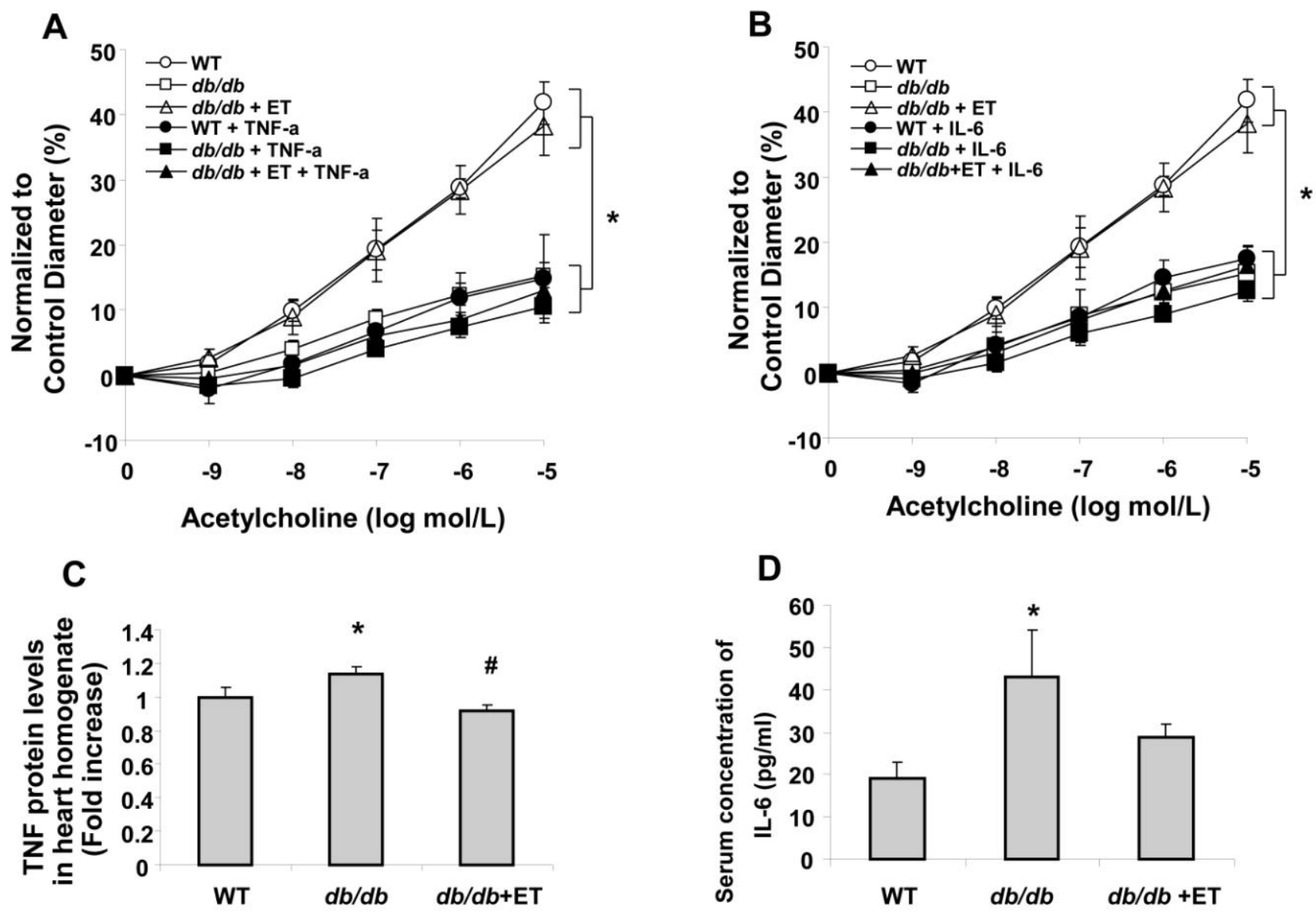

Figure 5 A-B. Incubation of tumor necrosis factor-alpha (TNF- $\alpha, 1 \mu \mathrm{g} / \mathrm{mL}, 1 \mathrm{hr}$ ) or interleukin-6 (IL-6, $5 \mu \mathrm{g} / \mathrm{mL}, 30$ min) impaired ACh-induced vasodilation in WT and $d b / d b+E T(n=3-17)$. C. Protein level of TNF- $\alpha$ were determined by enzyme-linked immunosorbent assay (ELISA). TNF- $\alpha$ protein levels in hearts were higher in $d b / d b$ mice compared to WT. Exercise decreased TNF- $\alpha$ protein levels $(n=6-7)$. D. Serum levels of IL-6 were measured by ELISA. Serum levels of IL- 6 were higher in $d b / d b$ compared to WT. Exercise decreased IL-6 levels but it did not reach to statistical difference (n=6-9). $* \mathrm{P}<0.05$ vs WT. \#P<0.05 vs $d b / d b$.

Endothelial dysfunction is an early indicator of increased risk for developing diabetes and restoring endothelial function is an important goal of therapeutic strategies for diabetes-induced CVD [3]. Exercise regimen is highly recommended in the therapies for type 2 diabetic patients and is believed to improve hyperglycemia, plasma lipid and insulin sensitivity as well as control of body mass [20,31,32]. Even though reduced body weight is often an important target achieved by life style changes such as exercise and calorie restriction, numerous studies suggest that salutary effects of an exercise regimen on CVD also occur independently of body mass [33-35]. There are several proposed mechanisms for how cardiometabolic benefits of exercise are obtained in diabetic patients. Exercise improves cardiovascular function by decreasing risk factors such as plasma lipids, blood glucose and/or body mass index [36,37]. However, long-term vigorous exercise is reported to ultimately result in a decrease in some of these metabolic parameters even though vascular function continues to improve [38]. In our study, 10 weeks of exercise training improved coronary arteriolar function without lowering blood glucose, CRP and body mass (lean and fat mass) as well as partial improvement in total cholesterol and insulin sensitivity, which may be associated with vascular endothelial function (Table1). Exercise also partially ameliorated blood glucose and insulin resistance in diabetic mice but not sufficiently to reach the levels seen in WT mice (Table1 and Figure1). Since ET completely reversed 
endothelial dysfunction of coronary arterioles in diabetes, this suggests that restoration may involve factors independent of body mass, hyperglycemia and insulin resistance.

Vascular reactivity from diabetic animals and humans exhibited attenuated endothelialdependent relaxation in response to ACh [5-7,34]. Consistent with previous studies, our results show that diabetic mice exhibited endothelial dysfunction compared to WT, and ET completely reversed coronary arteriolar endothelial dysfunction. However, endothelial-independent vasodilation to SNP was comparable among groups suggesting that ET improves vascular function via an endothelial-dependent route (Figure2). To investigate molecular mechanisms involved in beneficial effects of ET in terms of endothelial function, we incubated coronary arterioles with L-NAME and conducted immunoblots using heart tissue containing coronary arterioles. Evidence showed that sheer stress induced by exercise may alter protein expression of eNOS and phosphorylated eNOS [39]. In the present study, total eNOS and phosphorylation of eNOS were not altered in heart homogenates of WT and $d b / d b$ mice. Exercise upregulated phosphorylated eNOS activity in diabetes suggesting ET contributes to improve endothelial function by phosphorylation of eNOS at Ser1177.

Apart from eNOS expression, hyperglycemia results in increased oxidative stress in diabetes [40]. The formation of peroxynitrite occurs through a reaction between excessive superoxide and NO [41]. Superoxide dismutases (SODs) play an important role in scavenging superoxide to form hydrogen peroxide [42]. Three isoforms of SOD are currently known, but their relative role in protecting against diabetes-induced endothelial dysfunction is not fully elucidated. In our study, diabetic status did not change protein expression of SOD1 and 2, but exercise significantly increased these protein expressions. In addition, incubation of the superoxide scavenger, TEMPOL (a membrane-permeable superoxide mimetic) with blood vessels significantly improved endothelial function in coronary arterioles of diabetic subjects. However, coronary arterioles from exercise trained diabetes mice were not improved by incubation with TEMPOL suggesting that exercise may contribute to improvement of endothelial function by increasing SOD1 and 2.

Increased inflammation is a major risk factor in diabetes that may contribute to impaired endothelial function [1]. Type 2 diabetes is closely associated with increased levels of inflammatory cytokines such as TNF- $\alpha$, IL-6 and IFN- $\gamma$ [28]. TNF- $\alpha$ in the vasculature plays a critical role in endothelial dysfunction in type 2 diabetes [28]. Our results indicate that endothelial function is impaired in WT and $d b / d b+\mathrm{ET}$ mice when arterioles are incubated with TNF- $\alpha$ or IL-6 suggesting that pro-inflammatory cytokines may contribute to endothelial dysfunction in coronary circulation. In addition, protein expression of TNF- $\alpha$ is increased in $d b / d b$ and exercise significantly decreased TNF- $\alpha$ protein level. As we previously reported, serum level of IL-6 was increased in diabetic mice and exercise decreased IL-6.

In conclusion, the major finding of this study is that 10 weeks moderate intensity ET restored endothelial function of coronary arterioles by increasing NO bioavailability as well as reducing inflammation in type 2 diabetic mice. Exercise: 1) improved eNOS phosphorylation; 2) increased anti-oxidant enzymes such as SOD-1 and SOD-2, to increase NO bioavailability; 3 ) decreased proinflammatory cytokines such as TNF- $\alpha$ and IL-6. ET exerts numerous beneficial effects on endothelial function that appear to be remedial and/or protective in nature. ET has intrinsic value as an independent therapy and shows promise for use in combination with other therapies. Further detailed characterization of the therapeutic effects of exercise on vascular function will aid in devising clinical strategies to reduce risk of diabetes-induced myocardial infarction.

\section{Acknowledgements}

We thank Drs. Frank Booth and Matthew Laye for help in operating the DEXA machine.

\section{Disclosures}

None. 


\section{Sources of Funding}

This study was supported by grants from Pfizer Atorvastatin Research Award (2004-37, to C.Z.), American Heart Association SDG (110350047A, to C.Z.) and NIH grants (RO1HL077566 and RO1-HL085119, to C.Z.).

\section{References}

[1] Schalkwijk CG, Stehouwer CD. Vascular complications in diabetes mellitus: the role of endothelial dysfunction. Clin Sci (Lond) 2005;109 (2):143-59. DOI: 10.1042/CS20050025

[2] Andreassi MG, Barale R, Iozzo P, Picano E. The association of micronucleus frequency with obesity, diabetes and cardiovascular disease. Mutagenesis 2011;26 (1):77-83. DOI: 10.1093/mutage/geq077

[3] Karasu C. Glycoxidative stress and cardiovascular complications in experimentally-induced diabetes: effects of antioxidant treatment. Open Cardiovasc Med J 2010;4:240-56. DOI: 10.2174/1874192401004010240.

[4] Ding H, Triggle CR. Endothelial cell dysfunction and the vascular complications associated with type 2 diabetes: assessing the health of the endothelium. Vasc Health Risk Manag 2005;1 (1):55-71. DOI: http://dx.doi.org/10.2147/VHRM.S

[5] Beckman JA, Goldfine AB, Gordon MB, Garrett LA, Keaney JF, Jr., Creager MA. Oral antioxidant therapy improves endothelial function in Type 1 but not Type 2 diabetes mellitus. Am J Physiol Heart Circ Physiol 2003;285 (6):H2392-8. DOI: 10.1152/ajpheart.00403.2003

[6] Caballero AE. Endothelial dysfunction in obesity and insulin resistance: a road to diabetes and heart disease. Obes Res 2003;11 (11):1278-89. DOI: 10.1038/oby.2003.174

[7] Park Y, Yang J, Zhang H, Chen X, Zhang C. Effect of PAR2 in regulating TNF-alpha and $\mathrm{NAD}(\mathrm{P}) \mathrm{H}$ oxidase in coronary arterioles in type 2 diabetic mice. Basic Res Cardiol 2011;106 (1):111-23. DOI: 10.1007/s00395-010-0129-9

[8] Yang J, Park Y, Zhang H, Gao X, Wilson E, Zimmer W, Abbott L, Zhang C. Role of MCP-1 in tumor necrosis factor-alphainduced endothelial dysfunction in type 2 diabetic mice. Am J Physiol Heart Circ Physiol 2009;297 (4):H1208-16. DOI: 10.1152/ajpheart.00396.2009

[9] Gao X, Picchi A, Zhang C. Upregulation of TNF-alpha and Receptors Contribute to Endothelial Dysfunction in Zucker Diabetic Rats. Am J Biomed Sci 2010;2 (1):1-12. DOI: $10.5099 / a j 100100001$

[10] Moien-Afshari F, Ghosh S, Elmi S, Khazaei M, Rahman MM, Sallam N, Laher I. Exercise restores coronary vascular function independent of myogenic tone or hyperglycemic status in db/db mice. $A m J$ Physiol Heart Circ Physiol 2008;295 (4):H1470-80. DOI: 10.1152/ajpheart. $\underline{00016.2008}$

[11] Davignon J, Ganz P. Role of endothelial dysfunction in atherosclerosis. Circulation 2004;109 (23 Suppl 1):III27-32. DOI: 10.1161/01.CIR.0000131515.03336.f8

[12] Pepine CJ, Nichols WW. The pathophysiology of chronic ischemic heart disease. Clin Cardiol 2007;30 (2 Suppl 1):I4-9. DOI:/10.1002/clc.20048/pdf

[13] Tsao PS, Aoki N, Lefer DJ, Johnson G, 3rd, Lefer AM. Time course of endothelial dysfunction and myocardial injury during myocardial ischemia and reperfusion in the cat. Circulation 1990;82 (4):1402-12. DOI: 10.1161/01.CIR.82.4.1402

[14] Schachinger V, Britten MB, Zeiher AM.

Prognostic impact of coronary vasodilator dysfunction on adverse long-term outcome of coronary heart disease. Circulation 2000;101 (16):1899-906. DOI: 10.1161/01

[15] Lee S, Park Y, Dellsperger KC, Zhang C. Exercise training improves endothelial function via adiponectin-dependent and independent pathways in type 2 diabetic mice. Am J Physiol Heart Circ Physiol 2011. DOI: 10.1152/ajpheart.01306.2010 
[16] Lee S, Park Y, Zuidema MY, Hannink M, Zhang C. Effects of interventions on oxidative stress and inflammation of cardiovascular diseases. World J Cardiol 2011;3 (1):18-24. DOI: 10.4330/wjc.v3.i1.18

[17] Lakshmi SV, Padmaja G, Kuppusamy P, Kutala VK. Oxidative stress in cardiovascular disease. Indian J Biochem Biophys 2009;46 (6):421-40.

[18] Zhang $H$, Zhang C. Regulation of Microvascular Function by Adipose Tissue in Obesity and Type 2 Diabetes: Evidence of an Adipose-Vascular Loop. Am $J$ Biomed Sci 2009;1 (2):133-42. DOI: 10.5099/aj090200133

[19] Hansson GK. Inflammation, atherosclerosis, and coronary artery disease. $N$ Engl $J$ Med 2005;352 (16):1685-95. DOI:/full/10.1056/NEJMra043430

[20] Kim JA, Wei Y, Sowers JR. Role of mitochondrial dysfunction in insulin resistance. Circ Res 2008;102 (4):401-14. DOI:

\subsection{1/CIRCRESAHA.107.165472}

[21] Massett MP, Berk BC. Strain-dependent differences in responses to exercise training in inbred and hybrid mice. Am J Physiol Regul Integr Comp Physiol 2005;288 (4):R1006-13. DOI: 10.1152/ ajpregu.00476.2004

[22] Arnalich F, Hernanz A, Lopez-Maderuelo D, Pena JM, Camacho J, Madero R, Vazquez JJ, Montiel C. Enhanced acutephase response and oxidative stress in older adults with type II diabetes. Horm Metab Res 2000;32 (10):407-12. DOI:10.1055/S-2007-978662

[23] Hartge MM, Unger T, Kintscher U. The endothelium and vascular inflammation in diabetes. Diab Vasc Dis Res 2007;4 (2):848. DOI: $10.3132 / \mathrm{dvdr} .2007 .025$

[24] Zhang L, Zalewski A, Liu Y, Mazurek T, Cowan S, Martin JL, Hofmann SM, Vlassara H, Shi Y. Diabetes-induced oxidative stress and low-grade inflammation in porcine coronary arteries.
Circulation 2003;108 (4):472-8. DOI: 10.1161/01.CIR.0000080378.96063.23

[25] Yan SF, Ramasamy R, Naka Y, Schmidt AM. Glycation, inflammation, and RAGE: a scaffold for the macrovascular complications of diabetes and beyond. Circ Res 2003;93 (12):1159-69. DOI: 10.1161/01.RES.0000103862.26506.3D

[26] Stirban A, Negrean M, Stratmann B, Gawlowski T, Horstmann T, Gotting C, Kleesiek K, Mueller-Roesel M, Koschinsky T, Uribarri J, Vlassara H, Tschoepe D. Benfotiamine prevents macro- and microvascular endothelial dysfunction and oxidative stress following a meal rich in advanced glycation end products in individuals with type 2 diabetes. Diabetes Care 2006;29 (9):206471. DOI: $10.2337 / \mathrm{dc} 06-0531$

[27] Koh KK, Oh PC, Quon MJ. Does reversal of oxidative stress and inflammation provide vascular protection? Cardiovasc $\begin{array}{lll}\text { Res 2009;81 (4):649-59. DOI: } & \end{array}$ $10.1093 / \mathrm{cvr} / \mathrm{cvn} 354$

[28] Zhang C. The role of inflammatory cytokines in endothelial dysfunction. Basic Res Cardiol 2008;103 (5):398-406. DOI: 10.1007/s00395-008-0733-0

[29] Vasdev S, Gill VD, Singal PK. Modulation of oxidative stress-induced changes in hypertension and atherosclerosis by antioxidants. Exp Clin Cardiol 2006;11 (3):206-16.

[30] Morrell CN. Reactive oxygen species: finding the right balance. Circ Res 2008;103 (6):571-2. DOI: 10.1161/CIRCRESAHA.108.184325

[31] Tuomilehto J, Lindstrom J, Eriksson JG, Valle TT, Hamalainen H, Ilanne-Parikka P, Keinanen-Kiukaanniemi S, Laakso M, Louheranta A, Rastas M, Salminen V, Uusitupa M. Prevention of type 2 diabetes mellitus by changes in lifestyle among subjects with impaired glucose tolerance. $N$ Engl J Med 2001;344 (18):1343-50. DOI:/full/10.1056/NEJM20010503344180 1

[32] Boule NG, Haddad E, Kenny GP, Wells GA, Sigal RJ. Effects of exercise on 
glycemic control and body mass in type 2 diabetes mellitus: a meta-analysis of controlled clinical trials. JAMA 2001;286 (10):1218-27.

DOI: $\underline{10.1001 / \text { jama.286.10.1218 }}$

[33] Moien-Afshari F, Ghosh S, Elmi S, Rahman MM, Sallam N, Khazaei M, Kieffer TJ, Brownsey RW, Laher I. Exercise restores endothelial function independently of weight loss or hyperglycaemic status in $\mathrm{db} / \mathrm{db}$ mice. Diabetologia 2008;51 (7):1327-37. DOI: 10.1007/s00125-008-0996-x

[34] Zhang H, Zhang J, Ungvari Z, Zhang C. Resveratrol improves endothelial function: role of TNF\{alpha\} and vascular oxidative stress. Arterioscler Thromb Vasc Biol 2009;29 (8):1164-71. DOI: 10.1161/ATVBAHA.109.187146

[35] Gregg EW, Gerzoff RB, Thompson TJ, Williamson DF. Trying to lose weight, losing weight, and 9-year mortality in overweight U.S. adults with diabetes. Diabetes Care 2004;27 (3):657-62. DOI: $10.2337 /$ diacare.27.3.657

[36] Izquierdo-Porrera AM, Gardner AW, Powell CC, Katzel LI. Effects of exercise rehabilitation on cardiovascular risk factors in older patients with peripheral arterial occlusive disease. J Vasc Surg 2000;31 (4):670-7. DOI:10.1067/mva.2000.104422

[37] Goodyear LJ, Kahn BB. Exercise, glucose transport, and insulin sensitivity. Аппи Rev Med 1998;49:235-61. DOI: 10.1146/annurev.med.49.1.235

[38] Green DJ, Walsh JH, Maiorana A, Best MJ, Taylor RR, O'Driscoll JG. Exercise- induced improvement in endothelial dysfunction is not mediated by changes in CV risk factors: pooled analysis of diverse patient populations. Am J Physiol Heart Circ Physiol 2003;285 (6):H2679-87. DOI: 10.1152/ajpheart.00519.2003

[39] Gielen S, Schuler G, Adams V. Cardiovascular effects of exercise training: molecular mechanisms. Circulation 2010;122 (12):1221-38. DOI: 10.1161/CIRCULATIONAHA.110.93995 $\underline{9}$

[40] Esposito K, Nappo F, Marfella R, Giugliano G, Giugliano F, Ciotola M, Quagliaro L, Ceriello A, Giugliano D. Inflammatory cytokine concentrations are acutely increased by hyperglycemia in humans: role of oxidative stress. Circulation 2002;106 (16):2067-72. DOI: 10.1161/01.CIR.0000034509.14906.AE

[41] Jourd'heuil D, Jourd'heuil FL, Kutchukian PS, Musah RA, Wink DA, Grisham MB. Reaction of superoxide and nitric oxide with peroxynitrite. Implications for peroxynitrite-mediated oxidation reactions in vivo. J Biol Chem 2001;276 (31):28799805. DOI: $10.1074 /$ jbc.M102341200

[42] Fukai T, Ushio-Fukai M. Superoxide Dismutases: Role in Redox Signaling, Vascular Function and Diseases. Antioxid Redox Signal 2011. DOI:10.1089/ars.2011.3999 